\title{
Transformation of phosphorus in wetland biomass during pyrolysis
}

and hydrothermal treatment

Xiaoqiang Cui, ${ }^{*,+}$ Xiaoe Yang, ${ }^{\ddagger}$ Kuichuan Sheng, ${ }^{\S}$ Zhenli He," Guanyi Chen*,+

${ }^{\dagger}$ School of Environmental Science and Engineering/ Tianjin Key lab of Biomass Waste Utilization,

Tianjin University, Tianjin 300072, China

${ }^{\ddagger}$ Ministry of Education Key Laboratory of Environmental Remediation and Ecological Health, College of Environmental and Resource Sciences, Zhejiang University, Hangzhou 310058, China

${ }^{\S}$ College of Biosystems Engineering and Food Science, Zhejiang University, Hangzhou 310058, China

" Indian River Research and Education Center, University of Florida, Fort Pierce, FL 34951, USA.

Corresponding Authors:

*Xiaoqiang Cui, E-mail: cuixiaoqiang@tju.edu.cn; Tel: +86-022-87402072

*Guanyi Chen, E-mail: chen@tju.edu.cn; Tel: +86-022-87401929

Number of pages $=6$
Number of tables $=3$
Number of figures $=1$ 


\section{Calculation methods}

The recovery rate of $\mathrm{P}_{t}, \mathrm{P}_{\mathrm{o}}$, and $\mathrm{P}_{\mathrm{i}}$ in biochars after (hydro)thermal treatments was calculated by the following equation:

$$
R=\left(P_{B C} * \frac{Y}{P_{F S}}\right) * 100 \%
$$

where $P_{B C}$ is the content of $\mathrm{P}_{\mathrm{t}}, \mathrm{P}_{\mathrm{o}}$, and $\mathrm{P}_{\mathrm{i}}$ in biochars; $P_{F S}$ is the content of $\mathrm{P}_{\mathrm{t}}$, $\mathrm{P}_{\mathrm{o}}$, and $\mathrm{P}_{\mathrm{i}}$ in feedstocks; and $Y$ represent the yield of the biochars.

The proportion of different $\mathrm{P}$ pools in biochars could be calculated as follows:

$$
P=\left(\frac{P_{x}}{P_{t}}\right) * 100 \%
$$

where $P_{X}$ is the specific $\mathrm{P}$ species content by extraction, and $P_{t}$ is the total $\mathrm{P}$ content in the biochars. 
Fig. S1

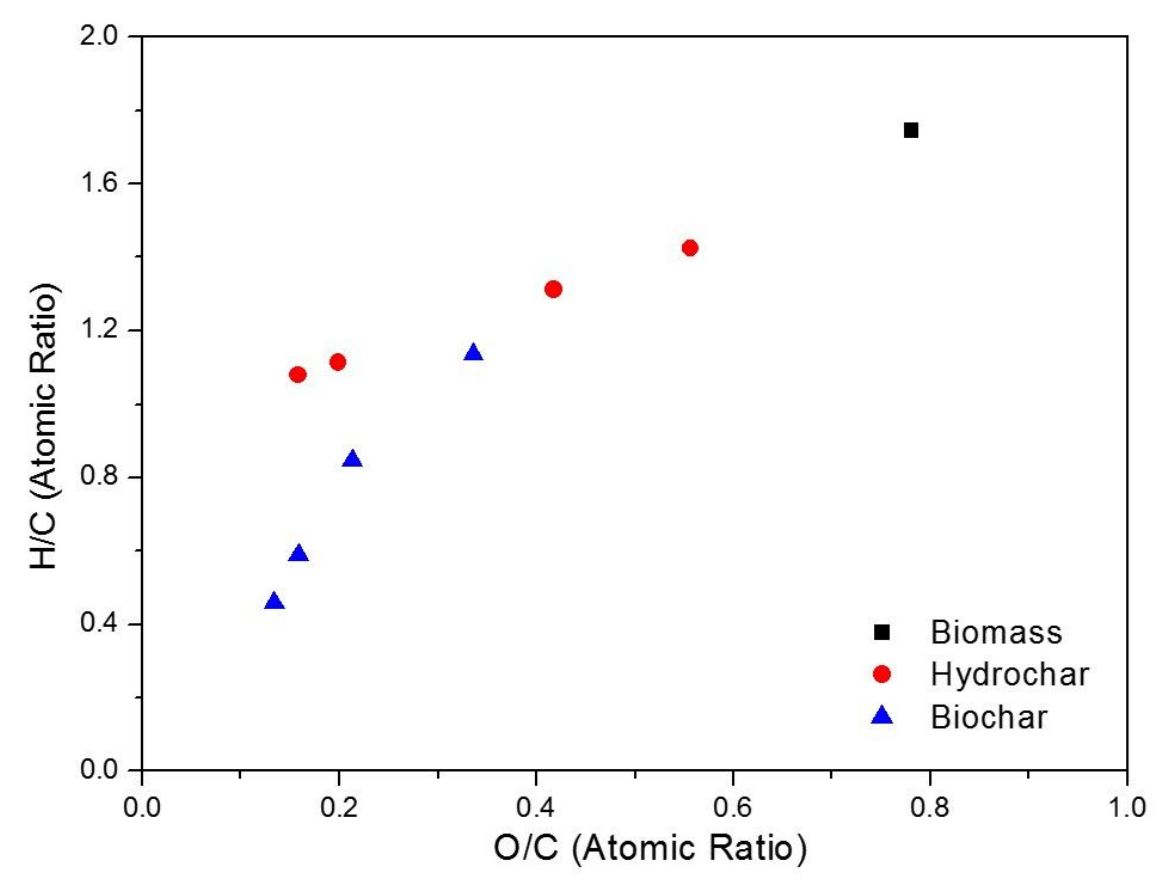

Fig. S1. Van Krevelen diagram for hydrochars and biochars derived from Napier grass at different temperatures. (Data taken from Table 1) 
Table S1. The total phosphorus $\left(\mathrm{P}_{\mathrm{t}}\right)$ concentration of the liquid products (LP) derived from Napier grass in HTC process at different temperatures.

\begin{tabular}{ll}
\hline Sample & $\mathrm{P}_{\mathrm{t}}\left(\mathrm{mg} \mathrm{L}^{-1}\right)$ \\
\hline LP200 & $492.73 \pm 11.40$ \\
LP220 & $172.77 \pm 1.89$ \\
LP240 & $57.22 \pm 0.26$ \\
LP260 & $36.70 \pm 0.82$ \\
\hline
\end{tabular}


Table S2. Amount of $\mathrm{P}_{\mathrm{t}}$ and corresponding recovery rate in Napier grass and the derived hydrochars and biochars extracted by EDTA-NaOH solution.

\begin{tabular}{lcc}
\hline Sample & $\mathrm{P}_{\mathrm{t}}\left(\mathrm{mg} \mathrm{g}^{-1}\right)$ & $\mathrm{P}_{\mathrm{t}}$ recovery (\%) \\
\hline $\mathrm{NG}$ & $7.47 \pm 0.09$ & 98.54 \\
NHC200 & $3.89 \pm 0.04$ & 95.84 \\
NHC220 & $10.49 \pm 0.04$ & 98.28 \\
NHC240 & $17.33 \pm 0.31$ & 94.71 \\
NHC260 & $15.53 \pm 0.22$ & 76.49 \\
NBC300 & $11.27 \pm 0.00$ & 87.80 \\
NBC400 & $13.35 \pm 0.22$ & 81.60 \\
NBC500 & $11.39 \pm 0.18$ & 65.91 \\
NBC600 & $10.77 \pm 0.44$ & 59.36 \\
\hline
\end{tabular}


Table S3. Relative abundance of P species in the EDTA-NaOH extracts of Napier grass and the derived hydrochars and biochars. Data were calculated from their ${ }^{31} \mathrm{P}$ NMR spectra by area integration using NUTS software.

\begin{tabular}{cccc}
\hline Sample & Ortho-P & $\begin{array}{c}\text { Monoester-P } \\
(\%)\end{array}$ & Pyro-P \\
\hline NG & 93.44 & 6.56 & 0.00 \\
NHC200 & 97.40 & 0.00 & 2.60 \\
NHC220 & 100.00 & 0.00 & 0.00 \\
NHC240 & 100.00 & 0.00 & 0.00 \\
NHC260 & 100.00 & 0.00 & 0.00 \\
NBC300 & 57.14 & 2.60 & 40.26 \\
NBC400 & 76.60 & 0.00 & 23.40 \\
NBC500 & 80.00 & 0.00 & 20.00 \\
NBC600 & 76.48 & 0.00 & 23.52 \\
\hline
\end{tabular}

